\title{
Broad complex tachycardia; never judge a book by its cover
}

\author{
M. V. Regeer · L. F. Tops · M. de Riva Silva
}

Accepted: 8 September 2020 / Published online: 2 October 2020

(C) The Author(s) 2020

A 69-year-old male presented to the emergency department with broad complex tachycardia (Fig. 1). He had been diagnosed with non-ischaemic cardiomyopathy with complete left bundle branch block (LBBB) and a left ventricular ejection fraction (LVEF) of $20 \%$ ten years earlier, for which he received cardiac resynchronisation therapy with defibrillator function (CRTD). He was a good responder with LVEF improving to $49 \%$ and functioning in New York Heart Association (NYHA) functional class I. A recent outpatient clinic electrocardiogram (ECG) showed sinus rhythm with biventricular pacing (Fig. 2).

On the day of admission he woke up with palpitations after an afternoon nap. He denied chest pain, dyspnoea and dizziness. Upon arrival of emergency medical services he was haemodynamically stable with a blood pressure of $124 / 76 \mathrm{~mm} \mathrm{Hg}$ and a broad complex tachycardia of initially $200 \mathrm{bpm}$, slowing down to $138 \mathrm{bpm}$ after $150 \mathrm{mg}$ amiodarone.

What is the origin of the broad complex tachycardia?

\section{Answer}

You will find the answer elsewhere in this issue.
Open Access This article is licensed under a Creative Commons Attribution 4.0 International License, which permits use, sharing, adaptation, distribution and reproduction in any medium or format, as long as you give appropriate credit to the original author(s) and the source, provide a link to the Creative Commons licence, and indicate if changes were made. The images or other third party material in this article are included in the article's Creative Commons licence, unless indicated otherwise in a credit line to the material. If material is not included in the article's Creative Commons licence and your intended use is not permitted by statutory regulation or exceeds the permitted use, you will need to obtain permission directly from the copyright holder. To view a copy of this licence, visit http://creativecommons.org/licenses/by/4.0/.

M. V. Regeer $(\bowtie) \cdot$ L. F. Tops $\cdot$ M. de Riva Silva

Department of Cardiology, Leiden Heart-Lung Center,

Leiden University Medical Center, Leiden, The Netherlands

m.v.regeer@lumc.nl 


\title{
Advertisement placed here.
}

\author{
ces bohn \\ CL van loghum
}

Houten 2021 


\title{
Advertisement placed here.
}

\author{
ces bohn \\ CL van loghum
}

Houten 2021 


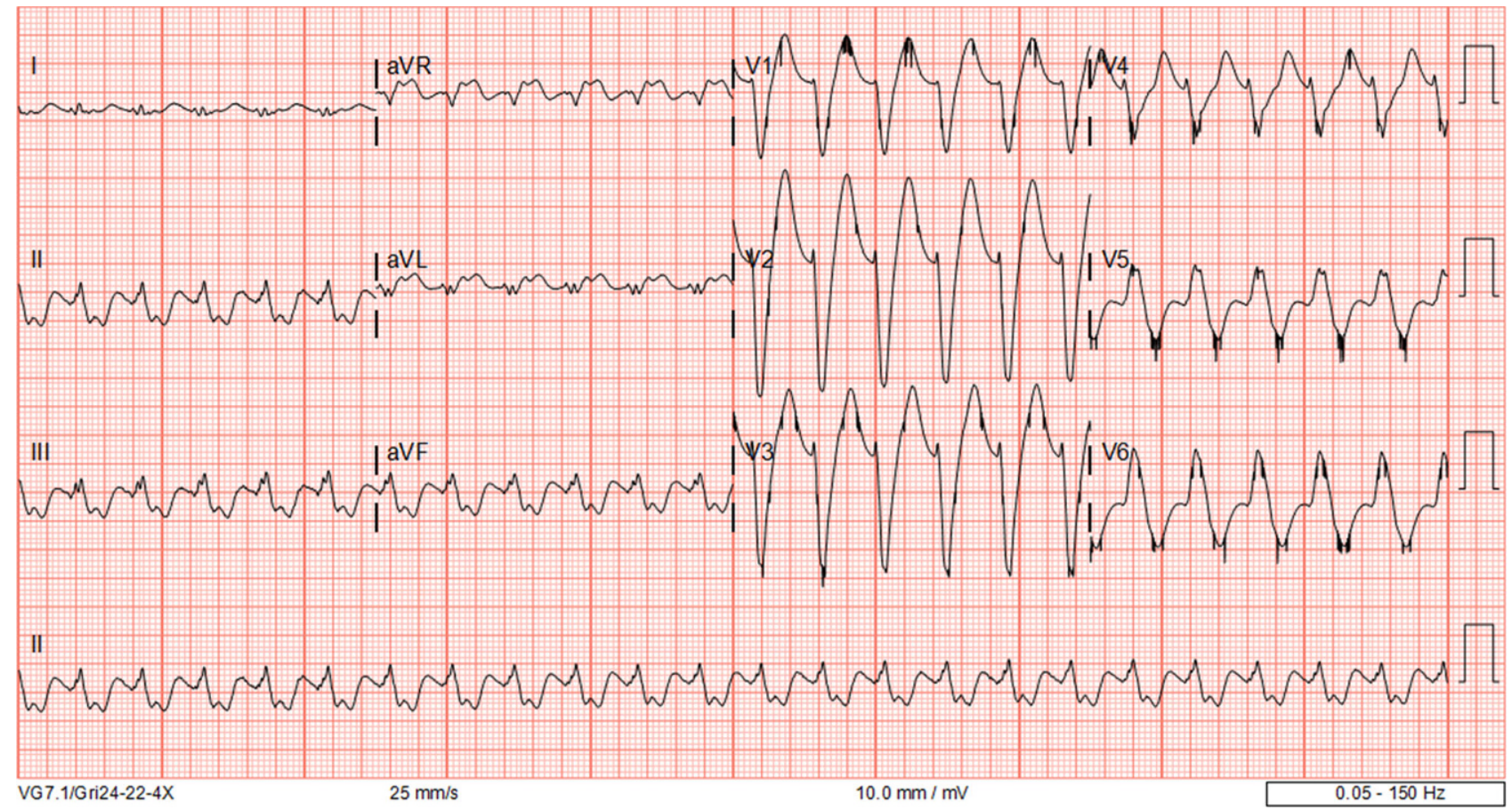

Fig. 1 Electrocardiogram of broad complex tachycardia

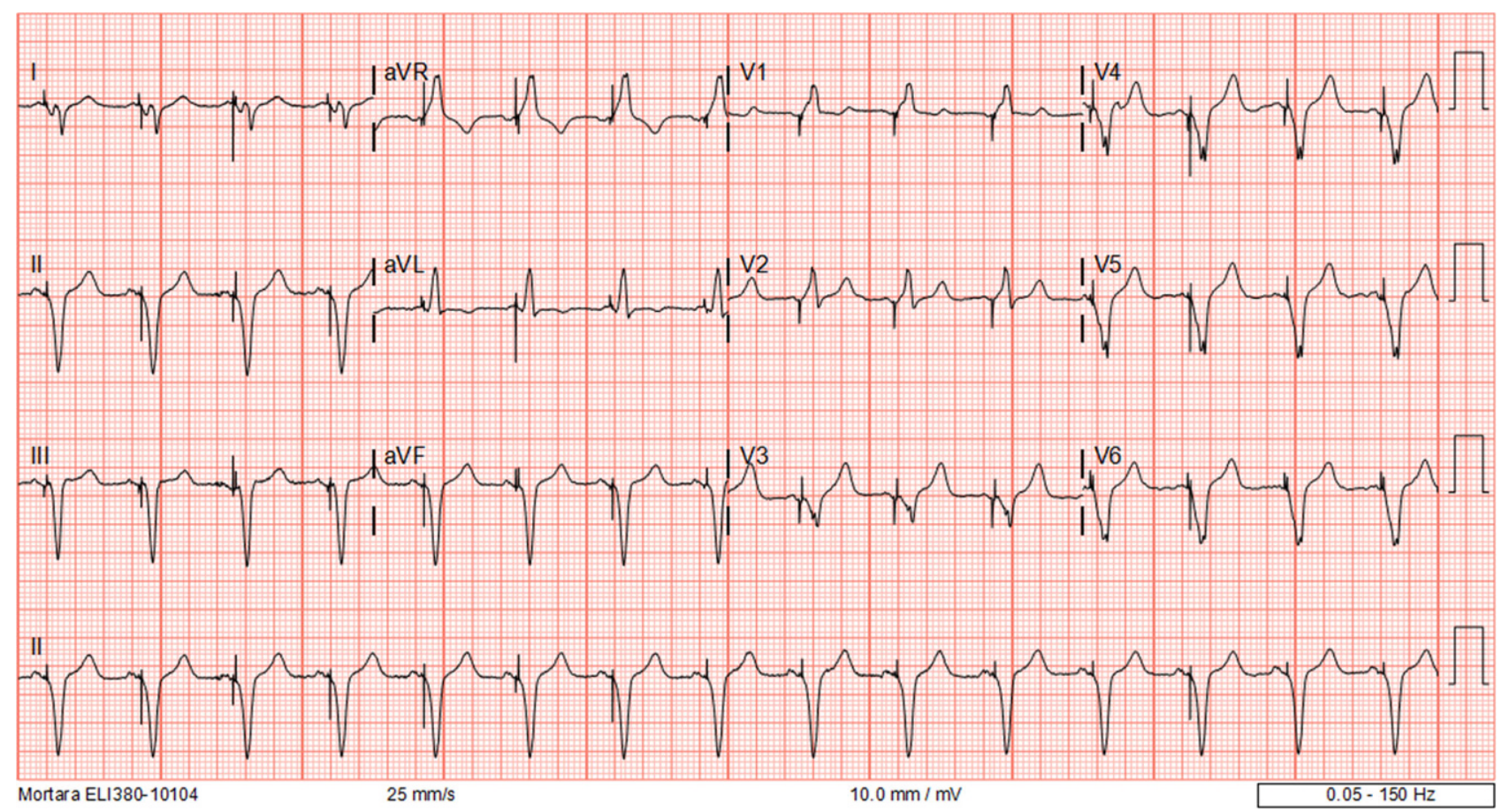

Fig. 2 Outpatient clinic electrocardiogram with biventricular pacing 